\title{
SATURATED ELECTRON DRIFT VELOCITY AT HIGH ELECTRIC FIELDS IN AIGaAs/GaAs/AIGaAs HETEROSTRUCTURES
}

\author{
J. Požela, K. Požela, A. Sužiedèlis, V. Jucienè, and Č. Paškevič \\ Semiconductor Physics Institute, Center for Physical Sciences and Technology, A. Goštauto 11, LT-01108 Vilnius, Lithuania \\ E-mail: pozela@pfi.lt
}

Received 16 November 2010; accepted 15 December 2010

\begin{abstract}
The experimental field dependences of electron drift velocity in the $\mathrm{Al}_{0.3} \mathrm{Ga}_{0.7} \mathrm{As} / \mathrm{GaAs}$ quantum well (QW) have no negative slope region and saturate at electric fields in the range of $5-10 \mathrm{kV} / \mathrm{cm}$. The saturated drift velocity in the narrow $(10 \mathrm{~nm})$ QW is lower and in the wide $(30 \mathrm{~nm}) \mathrm{QW}$ is larger than the saturated drift velocity in bulk GaAs. The enhancement of the saturated drift velocity is explained by the decrease in the equivalent intervalley and polar optical phonon scattering rates of electrons in upper valleys of a GaAs conduction band with the increase of a QW width. The calculation of these electron scattering rates shows that in $\mathrm{AlGaAs} / \mathrm{GaAs} \mathrm{QW}$ with a width larger than $10 \mathrm{~nm}$, the total confined electron-phonon scattering rate is lower compared with the electron-phonon scattering rate in bulk GaAs. Correspondingly, the electron drift velocity in $\mathrm{AlGaAs} / \mathrm{GaAs} \mathrm{QW}$ is larger than in bulk GaAs at electric fields higher than $10 \mathrm{kV} / \mathrm{cm}$.
\end{abstract}

Keywords: electron drift velocity, electron-phonon scattering, AlGaAs/GaAs heterostructures

PACS: 72.20.Ht, 72.10.Di, 73.40.Kp, 73.63.Hs

\section{Introduction}

The saturation of electron drift velocity at high electric fields in basic semiconductors ( $\mathrm{Si}, \mathrm{GaAs}$, InGaAs, and others) limits the enhancement of the main parameters of field effect transistors: the maximum cutoff frequency and gain. It has been experimentally observed that the electron drift velocity in GaAs is saturated at

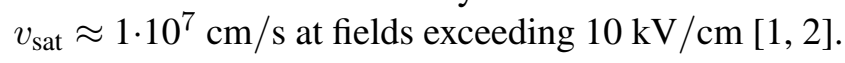
The highest (peak) electron drift velocity value $v_{\text {peak }}=$ $2 \cdot 10^{7} \mathrm{~cm} / \mathrm{s}$ is achieved at the threshold electric field $F_{\text {peak }} \approx 3 \cdot 10^{3} \mathrm{~V} / \mathrm{cm}$, when hot electron transfer from lower $\Gamma$ valley to higher $L$ valleys takes place $[3,4]$. In the region of electric fields $F=3-8 \mathrm{kV} / \mathrm{cm}$, the drift velocity-field characteristic, $v_{\mathrm{dr}}(F)$, has a negative differential slope, and a differential conductivity is negative $\left(\sigma_{\mathrm{d}}<0\right)$ due to this transfer.

The electron motion and drift velocity in a twodimensional (2D) electron gas at high electric fields is quite different from that for electrons in bulk samples. The high-field transport in low-dimensional structures is considered in [5-14]. The experimentally measured field dependences of electron drift velocity in HEMT channels show the absence of the region with $\sigma_{\mathrm{d}}<$ 0 [15-20].

Recently, it has been experimentally observed that the drift velocity in the GaAs QW at high electric fields
$(F \approx 10 \mathrm{kV} / \mathrm{cm})$ exceeds the saturated drift velocity in bulk material [19-23]. We assume that this phenomenon is a result of the decrease of the electronoptical phonon scattering rate (SR) in the QW as compared with the SR in a bulk semiconductor [16, 17].

In this paper, we are looking for conditions at which the saturated electron drift velocity in the GaAs QW can be larger than that in bulk GaAs at high electric fields of $F \approx 10 \mathrm{kV} / \mathrm{cm}$. We have estimated the intervalley and polar optical (PO) phonon SRs of electrons in the GaAs QW with different thicknesses at high electric fields in comparison with the SRs in bulk GaAs and carried out experimental testing of high-field electron drift velocity in the $\mathrm{Al}_{0.3} \mathrm{Ga}_{0.7} \mathrm{As} / \mathrm{GaAs}$ structures of different QWs.

\section{Equivalent intervalley and PO phonon scattering rates of electrons in the GaAs QW and bulk GaAs at high electric fields}

At high electric fields in the range of $8-12 \mathrm{kV} / \mathrm{cm}$, the most part of electrons in GaAs are transferred from $\Gamma$ valley to upper valleys of a conduction band [3, 4]. Therefore, we suppose that at the high electric fields, the electron drift velocity in GaAs is determined by the $\mathrm{SR}$ of electrons in upper $\mathrm{L}$ valleys. 
Let us compare the L-valley electron-phonon SR in the GaAs QW at high electric fields with the SR in bulk GaAs. For simplicity, we will consider the intrasubband electron-phonon scattering only in the lowest QW subband.

The frequency of transition of an electron with the initial wave vector $\boldsymbol{k}$ and the energy $E$ to the final state $\left(\boldsymbol{k}^{\prime}, E^{\prime}\right)$ by emission (absorption) of PO phonon with the energy $\hbar \omega_{0}$ will usually be expressed (see, for example, [24]) as

$$
\begin{aligned}
S_{\mathrm{s}}\left(\boldsymbol{k}, \boldsymbol{k}^{\prime}\right)= & \frac{2 \pi}{\hbar} V_{\mathrm{s}}(q) G\left(\boldsymbol{k}, \boldsymbol{k}^{\prime}\right) \delta\left(E^{\prime}-E \pm \hbar \omega_{0}\right) \\
& \times\left(N_{q}+\frac{1}{2} \pm \frac{1}{2}\right),
\end{aligned}
$$

where $\hbar$ is the Planck's constant, $\delta\left(E^{\prime}-E \pm \hbar \omega_{0}\right)$ is the Dirac delta function, $N_{q}=\left[\exp \left(\hbar \omega_{0} / k T\right)-1\right]^{-1}$ is the phonon occupation number, signs ' + ' and ' - ' refer to phonon emission and absorption, respectively. The overlap factor $G\left(\boldsymbol{k}, \boldsymbol{k}^{\prime}\right)$ over the normalization volume $V$ is equal to

$$
G\left(\boldsymbol{k}, \boldsymbol{k}^{\prime}\right)=\left|\int_{V} \varphi_{\mathrm{ei}} \varphi_{\mathrm{ef}} \varphi_{q} \mathrm{~d} V\right|^{2},
$$

where $\varphi_{\mathrm{ei}}, \varphi_{\mathrm{ef}}$ are the normalized electron wave functions in the initial and final states, respectively, $\varphi_{q}$ is the phonon wave function. We will use $\varphi_{\mathrm{e} z}=$ $\sqrt{2 / L_{z}} \sin \pi z / L_{z}$ as the $z$ component of the electron wave function in a rectangular QW and the FangHoward function $\varphi_{\mathrm{T}}=\sqrt{b^{3} / 2} z \exp (-b z / 2)$ with $b=3 / z_{0}$, where $z_{0}$ is the average width of the lowest subband inversion layer in a triangular QW.

The matrix element $V_{\mathrm{PO}}(q)$ of the electron-PO phonon scattering is taken as

$$
V_{\mathrm{PO}}(q)=\frac{e^{2}}{4 \pi \varepsilon_{0} q^{2}} \frac{\hbar \omega_{0}}{2}\left(\frac{1}{\chi_{\infty}}-\frac{1}{\chi_{0}}\right),
$$

where $e$ is the electron charge, $\boldsymbol{q}=\boldsymbol{k}-\boldsymbol{k}^{\prime}$ is the emitted (absorbed) phonon momentum, $\varepsilon_{0}$ is the permittivity of vacuum, $\chi_{\infty}=10.9$ and $\chi_{0}=12.3$ are the high and low frequency dielectric constants, respectively, and PO phonon energy is $\hbar \omega_{0}=0.036 \mathrm{eV}$ in GaAs. The matrix element $V_{\mathrm{s}}(q)$ of the intervalley scattering between equivalent $\mathrm{L}$ valleys can be expressed as

$$
V_{\text {int }}(q)=\frac{D_{\mathrm{LL}}^{2} \hbar^{2}}{2 \rho \hbar \omega_{\mathrm{LL}}}\left(N_{\mathrm{e}}-1\right),
$$

where in the case of GaAs the deformation potential for the scattering between equivalent $\mathrm{L}$ valleys is $D_{\mathrm{LL}}=$ $10^{9} \mathrm{eV} / \mathrm{cm}$, the material density is $\rho_{0}=5.3 \mathrm{~g} / \mathrm{cm}^{3}$, the intervalley phonon energy is $\hbar \omega_{\mathrm{LL}}=0.029 \mathrm{eV}$, the number of L valleys is $N_{\mathrm{e}}=4$.

The scattering rate of an electron with momentum $k$ is equal to

$$
W_{\mathrm{s}}(\boldsymbol{k})=\sum_{\boldsymbol{k}^{\prime}} S_{\mathrm{s}}\left(\boldsymbol{k}, \boldsymbol{k}^{\prime}\right)
$$

The mean value of the L-valley electron SR with a momentum loss can be estimated as

$$
\overline{W_{\mathrm{s}}}=\frac{\int W_{\mathrm{s}}(E) F_{T} g(E) f_{T}(E) \mathrm{d} E}{\int g(E) f_{T}(E) \mathrm{d} E},
$$

where $F_{T}=\left[1-f_{T}\left(E^{\prime}\right)\right] /\left[1-f_{T}(E)\right], g(E)$ is the electron density of states, and $f_{T}(E)=\{\exp [(E-$ $\left.\left.\left.E_{\mathrm{F}}\right) / k_{\mathrm{B}} T_{\mathrm{e}}\right]+1\right\}^{-1}$ is the symmetric part of the electron distribution function. We propose that temperature of hot electrons in L valleys at $10 \mathrm{kV} / \mathrm{cm}$ can be estimated taking into account the mean electron energy value of $k_{\mathrm{B}} T_{\mathrm{e}}=0.05 \mathrm{eV}$. This value is in agreement with the mean electron energy in L valleys at $10 \mathrm{kV} / \mathrm{cm} \mathrm{[3,} \mathrm{4].}$

The electron mobility limited by the intervalley and PO phonon scattering processes at the high fields can be expressed as

$$
\mu=\frac{e}{m_{\mathrm{L}}} \frac{1}{\bar{W}_{\mathrm{PO}}+\bar{W}_{\mathrm{int}}} .
$$

Then the ratio of the mean SR in the $\mathrm{QW}, \bar{W}_{\mathrm{QW}}=$ $\bar{W}_{\mathrm{POQW}}+\bar{W}_{\text {int QW }}$, to that in bulk, $\bar{W}_{\text {bulk }}=\bar{W}_{\mathrm{PO} \text { bulk }}+$ $\bar{W}_{\text {int bulk }}$, coincides with the ratio of the drift velocity in bulk, $v_{\text {dr bulk }}$, to that in the $\mathrm{QW}, v_{\mathrm{dr} \mathrm{QW}}$ :

$$
\frac{\bar{W}_{\text {bulk }}}{\bar{W}_{\mathrm{QW}}}=\frac{v_{\mathrm{dr} \mathrm{QW}}}{v_{\mathrm{dr} \text { bulk }}} .
$$

Figure 1 demonstrates the dependences of the calculated intrasubband SR (Eq. (6)) in a rectangular QW, $\bar{W}_{\mathrm{QW}}$, on the QW width $L_{z}$. One can see that for $L_{z}>$ $7 \mathrm{~nm}, \bar{W}_{\mathrm{QW}}$ becomes less than that in bulk material $\bar{W}_{\text {bulk }}$. This means that the electron drift velocity in the GaAs QW in the field range $F=8-12 \mathrm{kV} / \mathrm{cm}$ exceeds the drift velocity in bulk material for $L_{z}>7 \mathrm{~nm}$. For $L_{z} \approx 20-30 \mathrm{~nm}$, the electron drift velocity is $2-3$ times larger than the drift velocity in bulk material.

However, it is worth to note that with the increase of the QW width $L_{z}$, the energy gaps between the electron subbands decrease. In GaAs QW of width $L_{z}>30 \mathrm{~nm}$, the energy gap between lower subbands became less than $25 \mathrm{meV}$. Therefore, in the QW wider than $30 \mathrm{~nm}$, additional intrasubband as well as intersubband electron transfer in higher QW subbands manifests itself, and the electron-optical phonon SR is increased. Therefore, at 




Fig. 1. Calculated dependences of the mean intrasubband scattering rate of L-valley electrons in a rectangular GaAs $\mathrm{QW}, \bar{W}_{\mathrm{QW}}$, on the QW width $L_{z}$ (full curve) in comparison with the L-valley electron scattering rate in bulk GaAs, $\bar{W}_{\text {bulk }}$ (broken curve). Curves with indices 'Int' and 'PO' show contributions of intervalley and PO phonon scattering to the 'Total' scattering rate $\left(\bar{W}_{\mathrm{QW}}\right)$.

$L_{z} \rightarrow \infty$, the electron-optical phonon SR in the QW becomes near to that in bulk material.

The calculation of the L-valley electron mean SR in a triangular QW depending on the average width $z_{0}$ of the lowest subband inversion layer shows that, at $z_{0}>$ $3 \mathrm{~nm}, \bar{W}_{\text {QW }}$ is less than $\bar{W}_{\text {bulk. }}$. Therefore, the high-field drift velocity in a triangular QW exceeds that in bulk. In the case of $z_{0}=15 \mathrm{~nm}$, the drift velocity in the QW is four times larger than the drift velocity in bulk.

Therefore, the simple model of electron-optical phonon SR in a QW predicts that the intervalley and PO phonon SRs of electrons in a moderately wide GaAs QW at high electric fields $(8-12 \mathrm{kV} / \mathrm{cm})$ can be significantly less than those in bulk GaAs.

At higher electric fields $(F>12 \mathrm{kV} / \mathrm{cm})$, electrons in GaAs are transferred from $\mathrm{L}$ valleys to $\mathrm{X}$ valleys [3, 4]. The estimation of the mean SR (Eq. (6)) of $\mathrm{X}$-valley electrons taking into account the equivalent intervalley and PO phonon scattering is shown in Fig. 2. The following parameters are used in calculations: the deformation potential for scattering between $\mathrm{X}$ valleys, $D_{\mathrm{XX}}=10^{9} \mathrm{eV} / \mathrm{cm}$, the effective electron mass, $m_{\mathrm{X}}=0.41$, the number of $\mathrm{X}$ valleys, $N_{\mathrm{e}}=3$,

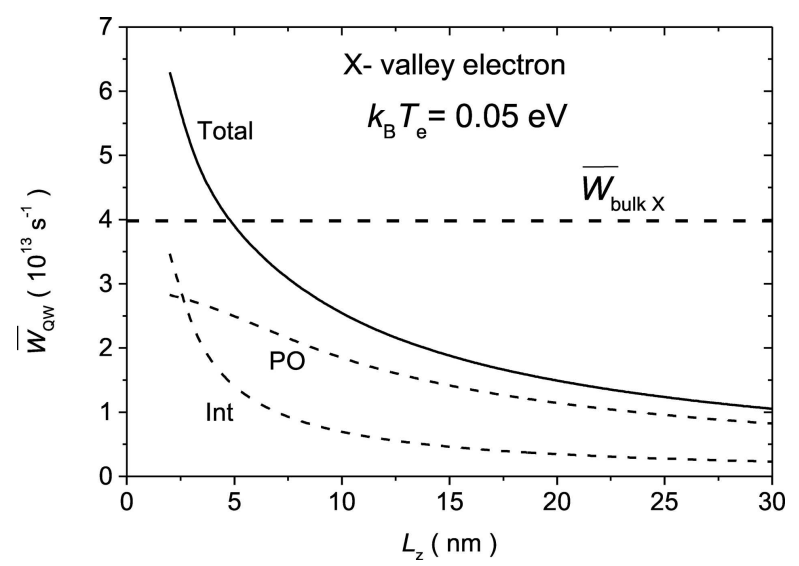

Fig. 2. Calculated dependences of the mean intrasubband scattering rate of X-valley electrons in a rectangular GaAs $\mathrm{QW}, \bar{W}_{\mathrm{QW}}$, on the QW width $L_{z}$ (full curve) in comparison with the X-valley electron scattering rate in bulk GaAs, $\bar{W}_{\text {bulk }}$ (broken curve). Other notations are as in Fig. 1.

and $k_{\mathrm{B}} T_{\mathrm{e}}=0.05 \mathrm{eV}$, because at the electric field of $10-30 \mathrm{kV} / \mathrm{cm}$, the X-valley electron mean energy corresponds to $k_{\mathrm{B}} T_{\mathrm{e}}=0.05 \mathrm{eV}[3,4]$. One can see that the X-valley electron-optical phonon SR in the QW at $L_{z}>5 \mathrm{~nm}$ is less than the SR in bulk GaAs. At $L_{z}=$ $15 \mathrm{~nm}$, the X-valley electron drift velocity in the QW exceeds that in bulk by 2 times.

The X-valley electron SR (Fig. 2) is higher than that for L-valley electrons (Fig. 1). Therefore, due to the electron L-X transfer at electric fields $F>12 \mathrm{kV} / \mathrm{cm}$, the current saturation and even negative differential conductivity can take place.

\section{Electron drift velocity in the AlGaAs/GaAs/AlGaAs QW at high electric fields}

The experimental measurements of the electron drift velocity at high electric fields in the $\mathrm{Al}_{0.3} \mathrm{Ga}_{0.7} \mathrm{As} /$ GaAs/ $/ \mathrm{Al}_{0.3} \mathrm{Ga}_{0.7} \mathrm{As}$ structures for different widths $L_{z}$ of the GaAs QW were performed. Table 1 shows the parameters of the investigated structures.

All samples have $100 \times 100 \mu \mathrm{m}^{2}$ ohmic contacts

Table 1 . The main parameters of the experimentally investigated samples.

\begin{tabular}{ccc}
\hline $\begin{array}{c}\text { AlGaAs/GaAs/AlGaAs } \\
\text { sample type }\end{array}$ & $\begin{array}{c}\text { GaAs QW width } \\
L_{z}, \mathrm{~nm}\end{array}$ & $\begin{array}{c}\text { Sheet electron } \\
\text { concentration } n_{\mathrm{s}}, \mathrm{cm}^{-2}\end{array}$ \\
\hline$A$ & 30 & $8.4 \cdot 10^{11}$ \\
$B^{*}$ & 30 & $5.9 \cdot 10^{11}$ \\
$C$ & 10 & $1.25 \cdot 10^{12}$ \\
$\mathrm{~T}^{* *}$ & $6^{* * *}$ & $2.6 \cdot 10^{12}$ \\
\hline
\end{tabular}

* with InAs barriers in the GaAs QW

** the single heterojunction $\mathrm{Al}_{0.3} \mathrm{Ga}_{0.7} \mathrm{As} / \mathrm{GaAs}$ modulation-doped structure (triangular $\mathrm{QW}$ )

*** width of the lowest subband inversion layer 


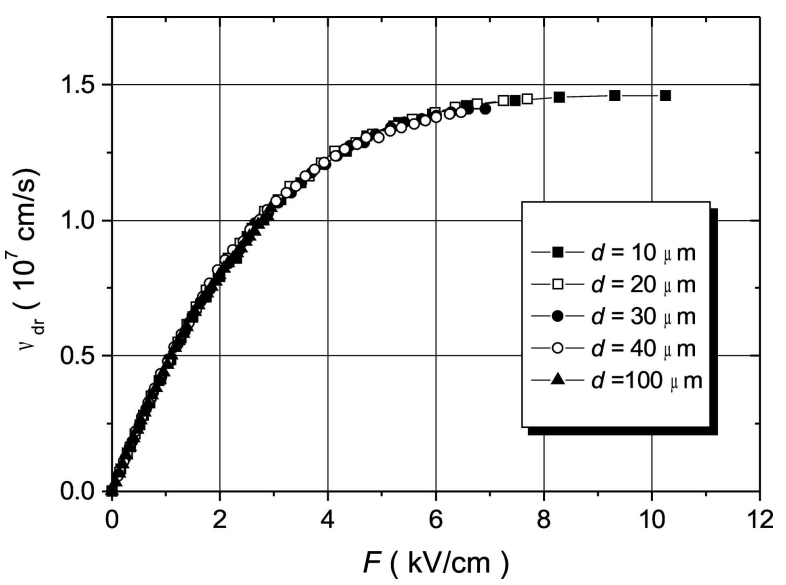

Fig. 3. Field dependences of the electron drift velocity $v_{\mathrm{dr}}$ in the channel of modulation-doped single heterojunction $\mathrm{Al}_{0.3} \mathrm{Ga}_{0.7} \mathrm{As} / \mathrm{GaAs}$ structure (triangular QW, T-type sample) with different spacing $d$ between the contacts.

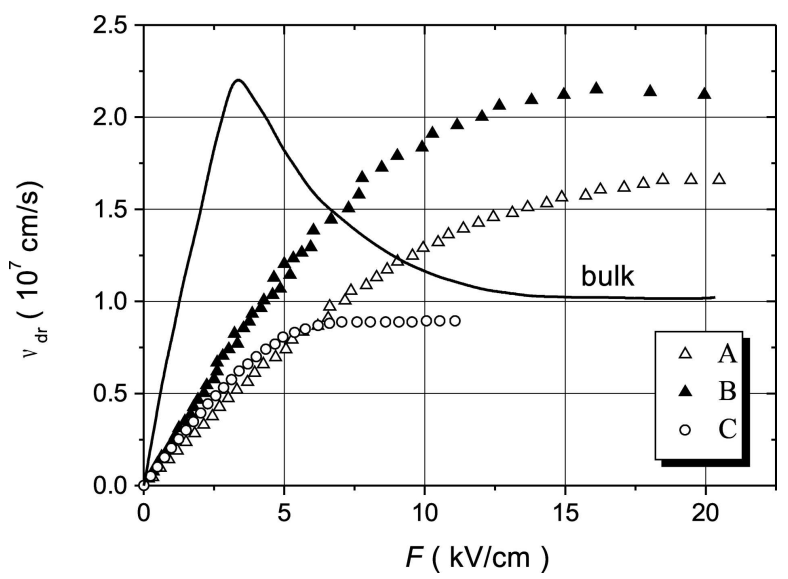

Fig. 4. Field dependences of the electron drift velocity $v_{\text {dr }}$ in the double-barrier $\mathrm{Al}_{0.3} \mathrm{Ga}_{0.7} \mathrm{As} / \mathrm{GaAs} / \mathrm{Al}_{0.3} \mathrm{Ga}_{0.7} \mathrm{As}$ structure with a different width of the GaAs QW: $30 \mathrm{~nm}$ in samples $A$ and $B$ and $10 \mathrm{~nm}$ in sample $C$. The spacing between the contacts is $d=10 \mu \mathrm{m}$. Sample $B$ has three thin (1 ML InAs) phonon barriers inserted into the GaAs layer. The full curve represents the field dependence of the drift velocity in bulk GaAs [1].

$(\mathrm{Au} / \mathrm{Ni} / \mathrm{Ge})$ with different spacing $d$ between them (from 10 to $100 \mu \mathrm{m}$ ).

Figures 3 and 4 show the field dependences of electron drift velocity in modulation-doped $\mathrm{Al}_{0.3} \mathrm{Ga}_{0.7} \mathrm{As} /$ $\mathrm{GaAs}$ structures with different $\mathrm{QW}$ widths. One can see that the field dependence $v_{\mathrm{dr}}(F)$ in the $\mathrm{QW}$ is sublinear and have no region with the negative slope where $\sigma_{\mathrm{d}}<$ 0 . It is worth to note that the threshold field for velocity saturation decreases about 3 times with increasing the QW width in a range of 10-30 nm (Fig. 4). These drift velocity field dependences are obtained from the experimental current-voltage characteristics $I(V)$ using the measured low-field sheet electron concentration $n_{\mathrm{s}}$.

Figure 3 demonstrates the $v_{\mathrm{dr}}(F)$ in the $\mathrm{QW}$ of the single heterojunction T-type structures (see Table 1). One can see that, at $F=10 \mathrm{kV} / \mathrm{cm}$, the electron drift velocity exceeds the maximum saturated drift velocity in bulk GaAs by a factor of 1.5. This is in agreement with the predicted increase in drift velocity in a triangular QW. The triangular QW approximation gives the calculated ratio of $W_{\text {bulk }} / W_{\mathrm{QW}}=1.8$ for $z_{0}=6 \mathrm{~nm}$ at $n_{\mathrm{s}}=2.6 \cdot 10^{12} \mathrm{~cm}^{-2}$.

Figure 4 shows field dependences of the electron drift velocity in the double barrier $\mathrm{Al}_{0.3} \mathrm{Ga}_{0.7} \mathrm{As} / \mathrm{GaAs} /$ $\mathrm{Al}_{0.3} \mathrm{Ga}_{0.7} \mathrm{As}$ structures ( $A$-, $B$-, and $C$-type samples).

In sample $C$ with the narrow $\mathrm{QW}$ of width $L_{z}=$ $10 \mathrm{~nm}$, the drift velocity at electric fields of $F>$ $6 \mathrm{kV} / \mathrm{cm}$ saturates and does not exceed the velocity in bulk GaAs. This is in agreement with the SR estimation for a narrow QW (see Fig. 1). The velocity saturation takes place at $F \geq 5 \mathrm{kV} / \mathrm{cm}$.

In samples $A$ and $B$ with a wider QW $\left(L_{z}=30 \mathrm{~nm}\right)$, the predicted increase of the drift velocity over that in bulk material is observed. Velocity saturation takes place at $F>12 \mathrm{kV} / \mathrm{cm}$. In sample $A$ at $F=15 \mathrm{kV} / \mathrm{cm}$, the drift velocity exceeds the saturated drift velocity in bulk by a factor of 1.6.

The largest increase of the drift velocity is observed experimentally in sample $B$. This structure contains three thin (1 monolayer of InAs) PO phonon barriers dividing the GaAs well into four narrow phonon wells. In papers [16, 17] it has been shown that the separation of the QW by thin InAs phonon walls and localization of the confined PO phonons in narrow phonon wells significantly decrease the electron-phonon SR. At $F=15 \mathrm{kV} / \mathrm{cm}$, the drift velocity in sample $B$ achieves $2.1 \cdot 10^{7} \mathrm{~cm} / \mathrm{s}$.

Therefore, the experimental data confirm the predicted increase of the electron drift velocity in a moderately wide GaAs QW over the maximum saturated drift velocity in bulk GaAs.

It is worth to note that similar experimental measurements of the drift velocity at high electric fields $F>$ $10 \mathrm{kV} / \mathrm{cm}$ were performed in Refs. [19] and [20]. These investigations have confirmed the increase of the drift velocity in the QW larger than $10 \mathrm{~nm}$ as compared to the saturated drift velocity in bulk GaAs.

\section{Conclusions}

We therefore conclude that the enhancement of the electron drift velocity at high electric fields $(>10 \mathrm{kV} / \mathrm{cm})$ in a wide $(L>10 \mathrm{~nm}) \mathrm{Al}_{0.3} \mathrm{Ga}_{0.7} \mathrm{As} /$ GaAs QW over the maximum saturated electron drift 
velocity in bulk material takes place. For the enhancement of the drift velocity in the QW, the decrease in the equivalent intervalley and polar optical phonon scattering rates of electrons in upper valleys of the GaAs conduction band with increasing the QW width is responsible.

\section{Acknowledgements}

We would like to thank V.P. Evtikhiev and A.S. Shkolnik (Ioffe Physicotechnical Institute, St. Petersburg) and G.B. Galiev and I.S. Vasil'evskii (Institute of the Microwave Semiconductor Electronics, Moscow) for providing the $\mathrm{AlGaAs} / \mathrm{GaAs} / \mathrm{AlGaAs}$ structures. The experimental samples were fabricated at Braun Submicron Research Center under the contract No. RITA-2003-506095.

\section{References}

[1] J.G. Ruch and G.S. Kino, Phys. Rev. 174, 921 (1968).

[2] G. Hill and P.N. Robson, Solid-State Electron. 25, 589 (1982).

[3] M. Shur, GaAs Devices and Circuits (Plenum Press, New York and London, 1987) pp. 35-36.

[4] J. Pozela and A. Reklaitis, Solid-State Electron. 23, 927 (1980).

[5] B.K. Ridley and N.A. Zakhleniuk, J. Phys. Condens. Matter. 8, 8525 (1996).

[6] B.K. Ridley and N.A. Zakhleniuk, J. Phys. Condens. Matter. 8, 8539 (1996).

[7] B.K. Ridley and N.A. Zakhleniuk, J. Phys. Condens. Matter. 8, 8553 (1996).

[8] N.A. Zakhleniuk, C.R. Bennett, B.K. Ridley, and M. Babiker, Appl. Phys. Lett. 73, 2485 (1998).

[9] B.K. Ridley, J. Phys. C 15, 5899 (1982).

[10] J. Požela, A. Namajūnas, K. Požela, and V. Jucienè, Physica E 5, 108 (1999).

[11] J. Požela, K. Požela, and V. Jucienè, Semiconductors 34, 1011 (2000) [Fiz. Tekh. Poluprovodn. 34, 1053 (2000)].
[12] D.R. Anderson, N.A. Zakhleniuk, M. Babiker, B.K. Ridley, and C.R. Bennet, Phys. Rev. B 63, 245313 (2001).

[13] A. Dmitriev, V. Kachorovski, M.S. Shur, and M. Stroscio, Int. J. High Speed Electron. Syst. 10, 103 (2000) / in: Frontiers in Electronics: From Materials to Systems, Selected Topics in Electronics and Systems Vol. 17, eds. Y.S. Park, S. Luryi, M.S. Shur, J.M. Xu, and A. Zaslavsky (World Scientific, Singapore, 2000) p. 119.

[14] M. Tomizawa, K. Yokoyama, and A. Yoshii, IEEE Electron Device Lett. 5, 464 (1984).

[15] B.K. Ridley, W.J. Schaff, and L.F. Eastman, J. Appl. Phvs 96. 1499 (2004)

[16] j̃. Požeia, K. Požeia, and V. Jucienè, Semiconductors 41, 1074 (2007) [Fiz. Tekh. Poluprovodn. 41, 1093 (2007)].

[17] Yu. Požela, K. Požela, V. Jucienè, S. Balakauskas, V.P. Evtikhiev, A.S. Shkolnik, Yu. Storasta, and A. Mekys, Semiconductors 41, 1439 (2007) [Fiz. Tekh. Poluprovodn. 41, 1460 (2007)].

[18] M. Ramonas, A. Matulionis, J. Liberis, L. Eastman, X. Chen, and Y.-J. Sun, Phys. Rev. B 71, 075324 (2005).

[19] V.G. Mokerov, I.S. Vasil'evskii, G.B. Galiev, J. Požela, K. Požela, A. Sužiedèlis, V. Jucienè, and Č. Paškevič, Semiconductors 43, 458 (2009) [Fiz. Tekh. Poluprovodn. 43, 478 (2009)].

[20] J. Požela, K. Požela, R. Raguotis, and V. Jucienè, Semiconductors 43, 1177 (2009) [Fiz. Tekh. Poluprovodn. 43, 1217 (2009)].

[21] J.K. Požela and V.G. Mokerov, Semiconductors 40, 357 (2006) [Fiz. Tekh. Poluprovodn. 40, 362 (2006)].

[22] J. Požela, K. Požela, A. Sužiedèlis, V. Jucienè, and V. Petkun, Acta Phys. Polon. A 113, 989 (2008).

[23] V.G. Mokerov, J. Pozela, K. Pozela, and V. Juciene, in: Nonequilibrium Carrier Dynamics in Semiconductors, Springer Proc. in Phys. Ser., Vol. 110, eds. M. Saraniti and U. Ravaioli (Springer, Berlin, Heidelberg, 2006) p. 245.

[24] V. Karpus, Dvimačiai elektronai (UAB Ciklonas, Vilnius, 2004) 530 p. [Two-dimensional Electrons, in Lithuanian]. 


\title{
SOTIES ELEKTRONU DREIFO GREITIS STIPRIUOSE ELEKTRINIUOSE LAUKUOSE IVAIRIALYČIUOSE AIGaAs/GaAs/AIGaAs DARINIUOSE
}

\author{
J. Požela, K. Požela, A. Sužiedèlis, V. Jucienè, Č. Paškevič
}

Fiziniu ir technologijos mokslu centro Puslaidininkiu fizikos institutas, Vilnius, Lietuva

\section{Santrauka}

Eksperimentiškai tirtos elektronų dreifo greičio priklausomybès nuo elektrinio lauko stiprio $\mathrm{Al}_{0,3} \mathrm{Ga}_{0,7} \mathrm{As} / \mathrm{GaAs}$ kvantinèse duobėse. Parodyta, kad šios priklausomybès neturi neigiamo polinkio srities laukuose nuo $5 \mathrm{iki} 10 \mathrm{kV} / \mathrm{cm}$. Soties dreifo greitis siaurose kvantinèse duobėse $(10 \mathrm{~nm})$ yra mažesnis, o platesnèse $(30 \mathrm{~nm})$ didesnis už soties dreifo greitị tūriniame GaAs. Soties dreifo greičio padidèjimas yra aiškinamas elektronų, esančių aukštesniuose GaAs laidumo juostos X ir L slèniuose, sklaidos tarpjuostiniais ir poliniais optiniais fononais silpnèjimu, kai kvantinès duobès plotis didèja. Atlikti šių sklaidų spartu skaičiavimai parodè, kad suminè elektronų sklaidos optiniais fononais sparta platesnèse už $10 \mathrm{~nm}$ AlGaAs/GaAs kvantinėse duobėse yra mažesnè negu elektronų sklaidos optiniais fononais sparta tūriniame GaAs. Atitinkamai, elektronu dreifo greitis $\mathrm{AlGaAs} / \mathrm{GaAs}$ kvantinèse duobėse yra didesnis negu šis greitis tūriniame GaAs stipresniuose negu $10 \mathrm{kV} / \mathrm{cm}$ elektriniuose laukuose. 